\title{
EDUCAÇAO FÍSICA E LIVRO DIDÁTICO: ENTRE O HIATO E O DESPERTAR
}

\author{
PHYSICAL EDUCATION AND TEXTBOOK: BETWEEN THE GAP AND THE \\ AWAKENING
}
EDUCACIÓN FÍSICA Y EL LIBRO DE TEXTO: ENTRE LA BRECHA Y EL DESPERTAR

\author{
Marcílio Barbosa Mendonça de Souza Júnior*, Lucas Vieira do Amaral**, \\ Marcelo Soares Tavares de Melo*, Suraya Cristina Darido***, \\ Ricardo Bezerra Torres Lima****
}

\section{Palavras-chave}

Livros de texto.

Materiais de ensino. Aprendizagem.
Keywords:

Textbooks.

Teaching materials. Learning.
Palabras clave Libros de texto. Materiales de enseñanza. Aprendizaje.
Resumo: 0 livro didático, ainda que receba algumas críticas, detêm potencial para contribuir com a qualificação do processo de ensino e aprendizagem dos diversos componentes curriculares. Entretanto, a disciplina de Educação Física tem se mostrado afastada desse tipo de recurso material, tendo algumas iniciativas esparsas do uso deste. Diante desse contexto, este estudo objetivou reconhecer, na literatura, quais os fatores que contribuíram para a constituição do hiato entre Educação Física e os livros didáticos e que elaborações foram realizadas recentemente neste campo sobre tal tipo de livro. Concluí-se que o legado histórico da Educação Física é um dos principais fatores propulsores desse hiato, mas que recentemente começa a ser minimizado por iniciativas de elaboração, discussão e uso do livro didático na área.

Abstract: The textbook also receiving some criticism, hold the potential to contribute to the qualification of the teaching and learning of the various curriculum components. However, it is common to notice that Physical Education has shown that remote resource type material, with some isolated initiatives of using this. In this context, this study aimed to recognize, in the literature, what factors contributed to the formation of the gap between physical education and textbooks and elaborations have been made recently in this field on such a book. We conclude that the historical legacy of Physical Education is one of the main driving factors of this hiatus, but recently began to be minimized by design initiatives and use of the textbook in the field.

Resumen: El libro de texto también recibir algunas críticas, mantenga el potencial de contribuir a la cualificación de la enseñanza y el aprendizaje de los diversos componentes del currículo. Sin embargo, es común a notar que la educación física ha demostrado que el material de tipo de recurso remoto, con algunas iniciativas aisladas de la utilización de esta. En este contexto, el presente estudio tuvo como objetivo reconocer, en la literatura, los factores que contribuyeron a la formación de la brecha entre la educación física y los libros de texto y elaboraciones se han hecho recientemente en este campo en un libro como éste. Llegamos a la conclusión de que el legado histórico de la Educación Física es uno de los principales factores de esta pausa, pero recientemente comenzó a ser minimizada por las iniciativas de diseño y el uso del libro de texto en el campo.
*Universidade de Pernambuco (UPE). Recife, PE, Brasil.

E-mail: marciliosouzaj @ hotmail.com

**Instituto Federal de Educação, Ciência e Tecnologia de Pernambuco. Recife, PE, Brasil.

E-mail: professorluca@ hotmail.com

***Universidade Estadual Paulista Júlio de Mesquita Filho (UNESP). Sao Paulo, SP, Brasil.

E-mail: surayacd@rc.unesp.br

****Universidade Federal Rural de Pernambuco (UFRPE). Recife, PE. E-mail: ricardobtlima@gmail.com

Recebido em: 30-06-2014

Aprovado em: 26-10-2014

(c) (1) () Licence 


\section{INTRODUÇÃOO}

O livro didático integra a cultura escolar brasileira há pelo menos dois séculos. Presente na história de nossa educação, o livro didático tem dado grandes contribuições, sendo um instrumento importantíssimo na ação pedagógica de alunos e professores. Este tem se configurado de diferentes formas, desde um auxiliar no processo educacional à uma importante fonte de conhecimento.

Entretanto, o livro didático também tem sido objeto altamente criticado no Brasil. Suas críticas vão desde a sua capacidade de veiculação de ideologias até as suas formas equivocadas de utilização, nas quais os docentes os usam como o único referencial para subsidiar a sua prática pedagógica, deixando que esses recursos materiais ditem as suas atividades (DARIDO et al., 2010), utilizando-os como "muletas" (MUNAKATA, 2003) durante o processo de ensino.

As críticas ao livro didático, após o período da ditadura militar, se intensificaram ao ponto de desencadearem um movimento para o seu abandono e condenação (MUNAKATA, 2003). No entanto ainda se faz muito presente na Educação Básica brasileira. Entende-se que os esforços para a superação das críticas não devem ser direcionados ao seu abandono/ condenação, mas às formas coerentes da sua utilização.

Compreende-se o livro didático como mais um recurso material com propriedades para contribuir na qualificação do processo de ensino e de aprendizagem dos diversos componentes curriculares da Educação Básica (Língua Portuguesa, Matemática, Geografia, História, Educação Física, dentre outros). Atualmente este tipo de livro pode ser escrito, o que é mais comum; oral, como o caso de livros falados para cegos; desenhado, são os livros de imagens; impresso, geralmente em papel; virtual, que são os livros digitais em ampla expansão. Sua elaboração, discussão e uso tem pautado a história da escola brasileira, sobretudo como recurso na difusão do conhecimento, tarefa central nesta instituição'. Tal recurso possibilita uma interação entre o objeto (conhecimento) e os sujeitos da educação (professores e alunos). Munakata (2003) ressalta que essa característica de "uso do professor e do aluno" é uma peculiaridade sinequa non do livro didático, ao ponto de afirmar que, se ele for utilizado por apenas um desses sujeitos, não poderá mais ser considerado como tal.

Os livros didáticos têm potencial para apoiar professores e alunos com os seus mais variados serviços, tais quais: 1) armazenar/ampliar informações; 2) complementar o ensino; 3) esclarecer determinado assunto; 4) ser fonte de consulta; 5) facilitar a aprendizagem; 6) promover o estudo independente; 7) promover a autodisciplina; 8) propiciar a integração entre a prática e a teoria; 9) auxiliar na revisão de conteúdos, entre outros (CARMO, 1999).

No entanto, mesmo diante de tantas contribuições importantes, a Educação Física tem se apresentado como um componente curricular obrigatório da Educação Básica de pouca relação com os livros didáticos, como se pode constatar na oferta de livros nas listas de materiais escolares, nas prateleiras de livrarias e na sua ausência no Plano Nacional do Livro Didático do Brasil (PNLD) que, por sua vez, representa o maior programa de livro didático do mundo (DARIDO et al., 2010).

Diante desse contexto, este estudo objetivou reconhecer, na literatura, quais os fatores que contribuíram para a constituição do hiato entre Educação Física e os livros didáticos e que elaborações foram realizadas recentemente neste campo sobre tal tipo de livro.

1 Para ampliar uma reflexão acerca do livro didático, sob diferentes enfoques e diante da realidade de diversas áreas, como língua portuguesa, matemática, ciências, história, geografia, sugerimos consultar a Revista Em Aberto, v. 16, n. 69, de jan./mar. de 1996, editada pelo Inep Instituto Nacional de Estudos e Pesquisas Educacionais Anísio Teixeira. Disponível em: <http://emaberto.inep.gov.br/index.php/emaberto/ issue/view/76>. Acesso em: 27 set. 2014. 


\section{PROCEDIMENTOS METODOLÓGICOS}

Este estudo é resultado de pesquisa bibliográfica, realizada na literatura específica do campo da Educação Física. Para tanto, usamos como fontes de coleta o banco de dados do Núcleo Brasileiro de Dissertações e Teses em Educação Física, Esportes, Educação e Educação Especial (NUTESES), os artigos presentes em periódicos brasileiros da área².

Os descritores que nortearam as buscas foram: "livro didático" e "livros didáticos". Vale salientar que utilizou-se aspas duplas para recuperar o termo exato, conforme orientação das próprias fontes.

No Sistema de Publicação Eletrônica de Teses e Dissertações do NUTESES, realizamos a busca simples, pois faz simultaneamente a pesquisa nos campos de "autor", "título", "contribuidor", "assunto", "resumo", "instituição de defesa", "área de concentração" e "linha de pesquisa". Entretanto selecionamos estudos vinculados ao campo da Educação Física brasileira e assim encontramos 2 (duas) Dissertações de Mestrado: Carmo (1999) e Rodrigues (2009).

Para a seleção dos periódicos os critérios foram: a) estarem presentes no Webqualis ${ }^{3}$ na área de avaliação Educação Física; b) serem de origem e circulação brasileira; c) apresentarem em seu título, pelo menos, um dos termos: Educação Física, Esporte, Movimento, Prática, Lazer, Atividade Física; d) disponibilizassem a sua base de dados online gratuitamente.

O Quadro 1 apresenta os periódicos que atenderam aos critérios anteriormente citados. Tal busca foi realizada na sessão: todos.

Quadro 1 - Periódicos que subsidiaram a pesquisa na literatura

\begin{tabular}{|l|c|}
\hline Título do periódico & Estrato \\
\hline Motriz: Revista de Educação Física (Online) & A2 \\
\hline Movimento (Porto Alegre. Online) & A2 \\
\hline Revista Brasileira de Medicina do Esporte (Impresso) & A2 \\
\hline Fisioterapia em Movimento (PUCPR. Impresso) & B1 \\
\hline Revista Brasileira de Ciências do Esporte & B1 \\
\hline Revista Brasileira de Educação Física e Esporte (Impresso) & B1 \\
\hline Licere (Centro de Estudos de Lazer e Recreação. Online) & B2 \\
\hline Pensar a Prática (Online) & B2 \\
\hline Pesquisas e Práticas Psicossociais & B2 \\
\hline Revista Brasileira de Atividade Física e Saúde & B2 \\
\hline Revista Brasileira de Ciência e Movimento & B2 \\
\hline Revista da Educação Física (UEM. Impresso) & B2 \\
\hline Arquivos em Movimento (UFRJ. Online) & B4 \\
\hline Atividade Física, Lazer \& Qualidade de Vida: Revista de Educação Física & B4 \\
\hline Caderno de Educação Física (UNIOESTE. Impresso) & B4 \\
\hline Ciência em Movimento (Impresso) & B4 \\
\hline Corpo em Movimento (ULBRA) & B4 \\
\hline Educação Física em Revista (Brasília) & B4 \\
\hline Esporte e Sociedade & B4 \\
\hline Motrivivência. Revista de Educação Física, Esporte, Lazer & B4 \\
\hline
\end{tabular}

2 Nossa busca aconteceu no mês de setembro de 2014.

3 Página da internet, ligada ao site da Coordenação de Aperfeiçoamento de Pessoal de Nível Superior (CAPES), que disponibiliza uma lista de periódicos de respaldo acadêmico-científico das diversas áreas e seus respectivos estratos. Essa página é alimentada pela própria CAPES que, por sua vez, avalia as revistas científicas periodicamente para atualizar os seus conceitos de qualidade (qualis A1, A2, B1, B2, B3, B4, $\mathrm{B} 5 \mathrm{e}$ C). 
Continuação do Quadro 1

\begin{tabular}{|l|c|}
\hline Perspectivas em Educação Física Escolar & B4 \\
\hline Recorde: Revista de História do Esporte & B4 \\
\hline Revista Brasileira de Educação Física, Esporte, Lazer e Dança (REFELD) & B4 \\
\hline Revista Brasileira de Docência, Ensino e Pesquisa em Educação Física & B4 \\
\hline Revista Brasileira de Psicologia do Esporte & B4 \\
\hline Revista Eletrônica de Estudo do Movimento Humano & B4 \\
\hline Revista Mackenzie de Educação Física e Esporte (Online) & B4 \\
\hline Teoria e Prática da Educação & B4 \\
\hline Ulbra e Movimento - Revista de Educação Física & B4 \\
\hline Revista de Psicologia: Teoria e Prática (Online) & B5 \\
\hline Acta do Movimento Humano & C \\
\hline Boletim Brasileiro de Educação Física (Brasília) & C \\
\hline Centro de Documentação e Biblioteca / Secretaria Municipal de Esportes, Lazer e Recreação. Revista Eletrônica & C \\
\hline Revista de Educação Física - Associação dos Professores de Educação Física de Londrina & C \\
\hline Total de periódicos: 34 & \\
\hline
\end{tabular}

Fonte: Autores.

Dentre os 34 (trinta e quatro) periódicos investigados, apenas 4 (quatro) apresentaram alguma publicação $0^{4}$ sobre o tema, conforme mostramos na Tabela 1.

Tabela 1 - Periódicos que apresentaram publicações sobre livro(s) didático(s)

\begin{tabular}{lc}
\hline Periódico & Quantidade de publicações encontradas \\
\hline Motriz: Revista de Educação Física (Online) & 23 \\
Movimento (Porto Alegre. Online) & 9 \\
Teoria e Prática da Educação & 2 \\
Motrivivência. Revista de Educação Física, Esporte, Lazer & 1 \\
\hline Total & 34 \\
\hline
\end{tabular}

Fonte: Autores.

Porém, nem todas as 34 (trinta e quatro) publicações foram aproveitadas para subsidiar o estudo, pois parte delas não discorria sobre o livro didático na Educação Física, apenas citavam o termo dentro do seu conteúdo, como observado na Tabela 2.

Tabela 2 - Total de publicações nos periódicos que tratam do(s) livro(s) didático(s) na Educação Física

\begin{tabular}{|c|c|}
\hline Periódico & Quantidade de publicações aproveitadas \\
\hline Motriz: Revista de Educação Física (Online) & 9 \\
\hline Movimento (Porto Alegre. Online) & 2 \\
\hline Motrivivência: Revista de Educação Física, Esporte, Lazer & 1 \\
\hline Total & 12 \\
\hline
\end{tabular}

Desse modo, chegou-se até os 12 (doze) textos: Botelho e Neira (2014); Darido et al. (2010); Diniz e Darido (2012); Fraiha, Darido e Rufino (2013); Galatti e Paes (2007); Galatti, 
Paes e Darido (2010); Impolcetto e Darido (2013); Rodrigues e Darido (2011); Paraiso (2011); Rufino e Darido (2011); Silva et al. (2001); e Souza Júnior, Melo e Santiago (2010).

Após a coleta iniciamos a análise de dados, na qual realizamos o tratamento, por inferências e interpretações. Para isso, os dados foram submetidos à técnica de análise de conteúdo (BARDIN, 2011), tomando por base o roteiro para o tratamento dos dados proposto por Souza Júnior, Melo e Santiago (2010).

De acordo com Souza Júnior, Melo e Santiago (2010, p. 34), essa técnica tem sido utilizada nas pesquisas qualitativas em Educação Física escolar e "[...] consiste num recurso técnico para análise de dados provenientes de mensagens escritas ou transcritas".

Contudo, existem diferentes tipos de análise de conteúdo, como por exemplo: de expressão, das relações, de avaliação, de enunciação e categorial temática (SOUZA JÚNIOR; MELO; SANTIAGO, 2010).

Nesse estudo, realizou-se a opção pela análise de conteúdo do tipo categorial temática, conforme indicadores do Quadro 2.

Quadro 2 - Indicadores para a análise de conteúdo

\begin{tabular}{|l|l|}
\hline \multicolumn{2}{|c|}{ Indicadores } \\
\hline Elemento central & O livro didático na Educação Física. \\
\hline Operacionalização & Distanciamento entre a Educação Física e os livros didáticos. \\
\hline Categorias analíticas & Livro didático; Educação Física. \\
\hline Categorias empíricas & $\begin{array}{l}\text { Fatores que contribuíram para o distanciamento existente entre a Educação Física e os livros } \\
\text { didáticos; Indícios da superação do status quo. }\end{array}$ \\
\hline
\end{tabular}

Fonte: Autores.

Na sequência, identificou-se, na literatura, as unidades de codificação/categorização de registro e de contexto, compondo o corpo das categorias empíricas, como observado no exemplo do Quadro 3.

Quadro 3 - Identificação das unidades de registro e contexto

\begin{tabular}{|c|c|c|}
\hline \multicolumn{2}{|c|}{ Categoria empírica } & \multirow{3}{*}{ Rodrigues (2009) } \\
\hline \multicolumn{2}{|c|}{$\begin{array}{l}\text { Fatores que contribuíram para o distanciamento } \\
\text { entre a educação Física e os livros didáticos }\end{array}$} & \\
\hline Unidades de contexto & Unidades de registro & \\
\hline \multirow{3}{*}{ História } & Saber fazer & $\begin{array}{l}\text { Historicamente a Educação Física esteve atrelada a uma tradição do } \\
\text { saber fazer, da realização dos movimentos, da vivência e experimentação } \\
\text { das brincadeiras, dos jogos e dos esportes, tais características tornaram } \\
\text { difícil estruturar esse material, assim como conceber sua aceitação junto } \\
\text { aos docentes e mesmo ao mercado editorial (p. 14). }\end{array}$ \\
\hline & \multirow{2}{*}{$\begin{array}{l}\text { Críticas do livro } \\
\text { didático }\end{array}$} & $\begin{array}{l}\text { O redirecionamento do pensar a respeito do objeto de estudo desse } \\
\text { componente curricular na escola, ocorreu a partir dos anos } 1980 \text {, no } \\
\text { mesmo período em que a produção de livro didático era intensamente } \\
\text { criticada. Essas críticas podem ter afastado os docentes, ou boa parte } \\
\text { deles, da construção e reflexão desses materiais (p. 14). }\end{array}$ \\
\hline & & $\begin{array}{l}\text { No receio de que essas posturas fossem adotadas pelos professores } \\
\text { da Educação Básica, os estudiosos da Educação Física acabaram se } \\
\text { abstendo da tarefa de elaborar tais materiais e mais do que isso não se } \\
\text { arriscaram a pesquisar profundamente o tema (p. 14). }\end{array}$ \\
\hline
\end{tabular}

Fonte: Autores. 
De tal modo, partiu-se para a realização das inferências que respaldaram as discussões que passamos a realizar.

\section{O HIATO ENTRE A EDUCAÇÃO FÍSICA E O LIVRO DIDÁTICO}

Os estudos da área da Educação Física que discorrem sobre livro didático ainda representam um número bastante reduzido, confirmando já inicial e quantitativamente 0 hiato existente. Perscrutou-se 0 acervo de 34 (trinta e quatro) periódicos e uma base de dados (NUTESES) da área e só foram localizados 14 (quatorze) publicações a esse respeito.

Galatti, Paes e Darido (2010) e Souza Júnior, Melo e Santiago (2013) apontam sua pouca disseminação e até inexistência. Os três últimos destacam, em pesquisa de campo, o ressentimento de professores de Educação Física, perante a ausência do livro didático, influenciando negativamente o planejamento e realização de suas intervenções pedagógicas. Vejamos trecho de uma fala apresentada por professor investigado.

Tá definido [nas outras áreas], não tem questionamento. Na educação física, tem. Não tem livro, não tem roteiro, a gente segue pelos PCNs. Que foram montados por determinadas pessoas. A gente não tem livros didáticos que possam servir como roteiros (SOUZA JÚNIOR; MELO; SANTIAGO, 2013, p. 43).

No entanto, as poucas publicações encontradas, em muito auxiliaram a compreensão do porquê a Educação Física e os livros didáticos se mostram distantes um do outro.

Tanto as duas dissertações encontradas, quanto sete dos artigos, realizaram em seus estudos análises acerca da implementação e uso do livro didático, precisando por vezes até elaborar tais livros em função de sua inexistência. Diniz e Darido (2012) faz isso associado ao conteúdo dança; Fraiha, Darido e Rufino (2013) ao ensino do basquetebol; Galatti e Paes (2007) e Galatti, Paes e Darido (2010) propõem um livro didático acerca dos Jogos Esportivos Coletivos; Impolcetto e Darido (2013) analisam o processo de construção coletiva deste tipo de livro no voleibol; Rodrigues e Darido (2011) avaliam a aplicabilidade na modalidade basquetebol; e Rufino e Darido (2011) analisam o impacto da implementação de um livro didático sobre 0 tema transversal da saúde.

Carmo (1999) e Rodrigues (2009), motivados pela qualificação de suas aulas, chegam a, previamente, elaborar um livro didático e verificar, por meio dos seus estudos de Mestrado, como esse recurso material é avaliado pelos sujeitos na prática pedagógica.

Mas, porque será que esses autores precisaram primeiro elaborar um livro didático para depois investigar as suas implicações na prática pedagógica? Não seria mais comum, a depender dos objetivos específicos dos estudos, avaliar as implicações de um livro didático de Educação Física já publicado?

Provavelmente! O problema é que no campo da Educação Física a produção e estudo do livro didático permanecem praticamente negligenciados (RODRIGUES, 2009). Desse modo, poucos são os livros didáticos de Educação Física que se tem registro. Segundo Rodrigues (2009, p. 4),

[...] um dos únicos livros que foi escrito para ser utilizado como material de apoio aos alunos foi elaborado por Teixeira [...] com nome de TDEF (Trabalho Dirigido de Educação Física). No levantamento realizado pelo Livres (Banco de Dados de Livros Escolares Brasileiros) apenas 11 manuais de Educação Física foram 
cadastrados e a maioria deles datados do início do século XX, a partir da década de 1990 nenhum livro foi cadastrado na base de dados desse componente curricular.

Mas, por que será que os livros didáticos se apresentam distantes da área da Educação Física, uma vez que esses recursos materiais são tão presentes no campo da maioria dos outros componentes curriculares obrigatórios? ${ }^{5}$. É o que aponta o depoimento de uma entrevistada por Souza Júnior, Melo e Santiago (2010, p. 43).

Têm isso... que é o diferencial... as outras disciplinas têm livro didático, têm uma organização já instituída de conteúdos, que podem ser mudados, mas que já foram instituídos, pela tradição, que vem lá da idade média, que vem lá de não sei onde, do trívio, do quadrívio [...] Educação física é uma história recente, sistematização de conhecimentos, para uma determinada ação na escola.

O passado normalmente aponta respostas para alguns fenômenos do presente. De acordo com Goellner (2004, p. 1) "[...] a memória e a história não nos aprisionam ao passado, mas nos conduzem a indagar e melhor compreender o presente."

A investigação da história da Educação Física aponta para alguns fatores que contribuíram para que ela se afastasse dos livros didáticos, como, por exemplo, as influências sociopolíticas (higienista, militarista e esportivista) que esse componente curricular recebeu ao passar dos anos no Brasil.

Diferente das outras disciplinas, a Educação Física (chamada, até então, de Ginástica) surge no contexto escolar brasileiro numa perspectiva higienista. Configurava-se numa atividade preocupada com os hábitos de higiene e saúde da população. Nessa ocasião, os profissionais da área médica eram quem, comumente, estavam à frente dessa prática.

Entretanto, é importante salientar que, nesse momento histórico, um material foi indicado como "livro didático" para a Educação Física das escolas públicas na cidade do Rio de Janeiro: o "Compendio de gymnastica e jogos gymnasticos escolares" de $1896^{6}$, de autoria de Arthur Higgins. Gomes-da-Silva (1999, p. 27) afirma que, "nessa época, a comissão da Diretoria Geral da Instrução Municipal emitiu um parecer afirmando que o livro seria um verdadeiro assessor aos professores primários [...]." Bem como, chama a atenção, para a forma como tal parecer fora concluído: "Tem, pois, o professor primário, neste livro um verdadeiro roteiro, e não terá mais a fazer que acompanhá-lo, para ensinar proficientemente esta disciplina" (HIGGINS ${ }^{7}$ apud GOMES-DA-SILVA, 1999, p. 28). Contudo, percebe-se que se trata muito mais de um "guia de orientação docente" do que de um livro didático de fato.

Fundamentando-nos em Munakata (2003) e em Carmo (1999) vemos que certos "livros didáticos", não intencionam o apoio e uso na interação dos principais sujeitos da ação pedagógica, professores e alunos, configurando-se como um guia de orientação do professor, pois apontam instruções, muitas vezes, prescritivas ao fazer docente, não servindo, especialmente, como fonte de consulta e aprendizagem do aluno, e, por sua vez, não permitindo o estudo independente por parte deste, em sua manipulação, por exemplo.

Entendemos que, no livro didático, a dimensão da prescrição sempre estará presente, mas não como doutrina restritiva e fechada, e sim como uma antecipação presente na

\footnotetext{
5 De acordo com um levantamento realizado pelo Livres (Grupo de pesquisa que passou a organizar a produção do livro didático no Brasil, mais especificamente na Biblioteca da Faculdade de Educação da Universidade de São Paulo), de 1990 até 2007 foram publicados 653 (seiscentos e cinquenta e três) livros didáticos de História e 698 (seiscentos e noventa e oito) de Língua Portuguesa, já em relação à Educação Física nenhum livro foi catalogado nesse período (RODRIGUES, 2009, p. 14).

6 Esse livro pautava-se no método ginástico Sueco-Belga (GOMES-DA-SILVA, 1999).

7 HIGGINS, Arthur. Compendio de Gymnastica e Jogos Escolares. Rio de Janeiro: Typografia do Jornal do Commercio, 1896.
} 
intencionalidade pedagógica, podendo assumir o caráter crítico, dialogado, amplo e aberto. Contudo essa intenção e prescrição não precisam se encerrar em si mesmas e muito menos num sujeito (elaborador do "livro") externo à prática pedagógica da sala de aula. É positivo que essas se baseiem numa relação de interesses entre os sujeitos pedagógicos (aluno, professor) e mais ainda no próprio objeto pedagógico (conhecimento). O livro didático precisa vislumbrar a organicidade da interação educacional, seja dentro ou fora da sala de aula e não ser um manual de conteúdos e estratégias, planificado em forma de documento, que dite as ações docentes na prática pedagógica.

Em seguida, a Educação Física numa perspectiva militarista toma destaque, uma disciplina voltada para a formação de indivíduos fortes e sadios para defender a pátria.

No entanto, vale destacar que, nesse período, os instrutores dispunham de outro "livro", guia de orientação, o "Regulamento ํo 7 de Educação Física", mais conhecido por método ginástico francês. Esse livro, publicado em 1934 no Brasil, utilizado nas escolas de todo o território nacional, corresponde à tradução integral do Regulamento Geral de Educação Física francês pela Escola de Educação Física do Exército. Sua publicação foi motivada, inclusive, pela falta de um guia orientador da Educação Física nos corpos de tropa e estabelecimentos militares.

Nesse contexto, a reprodução de movimentos corporais era muito vivenciada, reflexo das orientações advindas do próprio Regulamento no 7. É tanto que, termos como "sessões de estudos" e "lições", os quais estão presentes na maioria dos livros didáticos, têm a seguinte conotação no referido livro:

As sessões de estudos eram caracterizadas como momentos realizados no início ou durante a instrução [...] em que os alunos receberiam orientações acerca do melhor modo de execução dos movimentos [...]. As lições de Educação Física deveriam ser compostas por exercícios variados e combinados, e a recomendação era: na fase preparatória, realizar exercícios de evolução, de flexionamento de braços, de pernas e de tronco; na fase da sessão propriamente dita, os exercícios com base em marchas, escaladas, equilíbrios, saltos, levantamentos e transportes, corridas, lançamentos e ataques e defesas. [...] na fase da volta à calma, realizar exercícios de fraca intensidade [...] (SOUZA JÚNIOR, 1999, p. 169).

Embora esse recurso material apresentasse uma organização do conhecimento (baseado em princípios anátomo-fisiológicos) por meio de orientações, explicações e ilustrações, dentre outros, não se pode considerá-lo como um livro didático, pois não se configurava como um recurso material de uso do professor e dos alunos, um objeto de interação entre esses sujeitos na qualificação do processo de ensino-aprendizagem, mas sim, um livro de uso exclusivo do instrutor.

Logo após, em pleno regime militar, a partir da década de 1960, a Educação Física foi altamente influenciada pelo fenômeno esportivo. Este foi o caso do "Guia para aulas de Educação Física", publicado, pelo Ministério da Educação e Cultura (MEC), em 1971, elaborado por Mário Carvalho Pini e Valdir Barbanti, com o patrocínio da Empresa Alpargatas S.A..

Aqui os termos "Educação Física" e "esporte" eram entendidos como sinônimos; foi a época do binômio Educação Física/Esporte. Na perspectiva esportivista priorizava-se a detecção de talentos esportivos que tivessem potencial para representar o país em competições nacionais e internacionais. Nesse contexto, estavam presentes o professor-técnico e o aluno-atleta. 
Como se percebe, as perspectivas iniciais da Educação Física, ainda que fizessem referência a livros, possuíam caráter prescritivo, como guia orientador da atuação do professor/instrutor. Identifica-se, portanto, a ausência de um recurso material que ajudasse não só o professor a dar aulas, mas, também, os alunos a apreenderem o conteúdo de ensino.

De acordo com Paula (2003, p. 9), historicamente foi construído que "[...] na aula de Educação Física não se reflete, não se discute, enfim, não se pensa e, portanto, não se lê, mas apenas se executa".

Segundo Darido et al. (2010, p. 452),

$\mathrm{Na}$ verdade, as aulas de Educação Física se restringiam (e até certo ponto se mantém assim) a oferecer um conhecimento que advém da repetição e da prática dos movimentos. Essa concepção, certamente, afastou a disciplina dos livros didáticos dos alunos. É preciso lembrar, inclusive que a legislação da Educação Física até a aprovação da última Lei de Diretrizes e Bases (BRASIL/1996) reforçava a concepção de Educação Física como atividade, que segundo Castellani Filho (1988) dava a ela uma conotação de um fazer por fazer.

Esse caráter de atividade, que legalmente fora definido pelo Parecer $n . .853 / 71$ e Resolução $n . .08 / 71$, é um importante fator que também pode ter contribuído para 0 distanciamento entre a Educação Física e os livros didáticos. Por meio do estudo de Souza Júnior (1999) pode-se entender que o referido parecer apresentava a distinção entre o que se caracterizava por "atividade" e por "disciplina".

Desse modo, acredita-se que, por não se configurar, à época, como uma disciplina, não tendo caráter formal no currículo escolar, não dispondo de um conteúdo programático formal, ou seja, por ser concebida como uma atividade, não se percebia a necessidade de se ter propriamente livros didáticos de Educação Física.

Rodrigues (2009, p. 14) aponta fatores históricos para explicar a negligência da Educação Física quanto aos livros didáticos, o autor

\footnotetext{
[...] refere-se ao fato de que historicamente a Educação Física esteve atrelada a uma tradição do saber fazer, da realização dos movimentos, da vivência e experimentação das brincadeiras, dos jogos e dos esportes, tais características tornaram difícil estruturar esse material, assim como conceber sua aceitação junto aos docentes e mesmo ao mercado editorial.
}

Carmo (1999) confirma essa difícil aceitação junto aos docentes, ao afirmar que ao tentar confeccionar o livro didático para o ensino do futebol com outros profissionais da área da Educação Física, percebeu certo descrédito por parte deles, os quais não se propuseram a participar da elaboração do material. Então, após essa constatação, o referido autor fez a opção de elaborá-lo junto com os seus alunos.

Conforme Rodrigues (2009, p. 14),

Outro fator também contribuiu para as restrições ao livro didático na Educação Física. $\mathrm{O}$ redirecionamento do pensar a respeito do objeto de estudo desse componente curricular na escola, ocorreu a partir dos anos 1980, no mesmo período em que a produção de livro didático era intensamente criticada. Essas críticas podem ter afastado os docentes, ou boa parte deles, da construção e reflexão desses materiais. 
Essa tradição do saber fazer, essa visão de atividade, contribuiu, portanto com a ideia de que o objeto de estudo da Educação Física se restringiria a um mero "fazer prático destituído de uma reflexão teórica". No entanto isto é uma visão, no mínimo distorcida deste componente do currículo escolar.

Paraiso (2011), tendo como uma das fontes de pesquisa um livro didático na Educação Física, defende que este componente curricular seja tratado como disciplina escolar, reconhecido como um campo do conhecimento com conteúdos próprios que precisam ser levados às gerações presentes e futuras.

Fraiha, Darido e Rufino (2013), fortalecendo este pensamento, afirmam que novas propostas pedagógicas, seja na Educação Física escolar, na Pedagogia do Esporte ou mesmo no ensino específico do basquetebol, apontam para a abordagem dos conteúdos não somente, não apenas, de maneira procedimental, enfatizando o saber fazer, sendo necessário abordar, conjuntamente, as dimensões conceituais e atitudinais, podendo o livro didático ser um importante aporte.

Diniz e Darido (2012) e Rodrigues e Darido (2011), apontam que o livro didático pode ser uma alternativa para lidar com dificuldades pedagógicas, por exemplo a falta de materiais didáticos. Galatti e Paes (2007) e Galatti, Paes e Darido (2010) indicam o livro didático como mediador para abordar os conteúdos de ensino, inclusive permitindo a construção de sequências didáticas.

A partir do LD, considerando-o um mediador entre a criança e os JECs, o LD ajuda o professor na organização dos conteúdos do trabalho, sem substituí-lo, tampouco sem diminuir sua importância ao longo do processo de ensino aprendizagem, uma vez que ele continuará a ser o principal mediador do processo, uma vez que sua formação profissional e autonomia deve permitir ao profissional potencializar este material (GALATTI; PAES; DARIDO, 2010, p. 760).

\section{LIVROS DIDÁTICOS DE EDUCAÇÃO FÍSICA}

É fato que o livro didático, mesmo como recurso para a interação entre conhecimentos, alunos e professores, apesar da sua indiscutível importância e contribuição, é alvo de uma série de críticas, as quais versam sobre: a ideologia veiculada em seu conteúdo; por ser, muitas vezes, o único recurso material utilizado pelo professor para guiar o processo de ensinoaprendizagem; por gerar uma postura passiva do aluno no ato de aprender; por ser considerado como "muleta" do professor, sem a qual ele dificilmente leciona, dentre outros.

Nesse ínterim, Rodrigues (2009, p. 13) alega que:

[...] no receio de que essas posturas fossem adotadas pelos professores da Educação Básica, os estudiosos da Educação Física acabaram se abstendo da tarefa de elaborar tais materiais e mais do que isso não se arriscaram a pesquisar profundamente 0 tema.

Assim, entende-se que a trajetória histórica percorrida pela Educação Física no contexto escolar não foi favorável para que se estabelecesse uma relação com os livros didáticos, tendo em vista que por várias décadas ela foi materializada como uma atividade pautada no "fazer por fazer", no "saber fazer", na reprodução de movimentos corporais, em detrimento de um componente curricular de fato. 
Por outro lado, percebe-se, na literatura, algumas experiências, ainda que esparsas, na elaboração, discussão e o uso de livros didáticos em Educação Física. Alguns mais antigos outros mais recentes, uns construídos por meio de editoras privadas e outros por meio de um processo coletivo e público, uns destinados para o Ensino Fundamental e outros para o Ensino Médio.

Um dos primeiros livros didáticos de Educação Física, pensando na interação professor-aluno, foi produzido, em 1976, por uma editora privada, intitulado: "Trabalho Dirigido de Educação Física (TDEF)", e de autoria de Hudson Ventura Teixeira (DARIDO et al., 2010, DINIZ; DARIDO, 2012). Esse livro foi bastante difundido na área, tratando-se de uma obra destinada ao primeiro segmento do Ensino Fundamental, trazendo conteúdos de ginástica, jogos, desporto, atletismo, handebol, basquetebol, voleibol e da ginástica olímpica ao término de cada unidade. Expressa a época da Educação Física como atividade curricular.

De acordo com Rodrigues (2009, p. 14), esse livro "[...] foi disseminado entre os professores da Educação Básica, embora tivesse sido elaborado para os alunos. Apesar disso, não obteve a devida atenção do meio acadêmico".

Outro livro didático de Educação Física, construído e vendido, a partir de 1996, sobre a lógica da editoração privada9 , é o "Educação Física e Desportos", também de Hudson Ventura Teixeira.

Esse livro, uma reformulação do publicado em 1976, aparentando uma linguagem mais madura como se quisesse atingir alunos a partir do sexto ano do fundamental, apresenta os mesmos conteúdos temáticos de cada unidade e na mesma ordem, acrescido da unidade de futebol/futsal, estando a ginástica olímpica ao término da obra, como uma unidade própria.

Por outro lado, na rede pública, alguns estados e municípios brasileiros produziram os seus próprios livros didáticos de Educação Física. Como a intenção deste artigo não foi esgotar análises de livros didáticos sobre Educação Física mais recentes, apenas situamos alguns que a pesquisa nos periódicos apontou. Entretanto temos conhecimentos de outras elaborações em estados e municípios ${ }^{10}$.

Um deles foi lançado em 2006, é o "Livro Didático Público de Educação Física do Estado do Paraná", o qual se configura como o primeiro livro didático público de Educação Física com linguagem voltada para o aluno em interação com o professor. Botelho e Neira (2014) analisaram uma produção acerca de uma tese de doutorado, que procurou compreender como se constituiu o saber no discurso pedagógico do texto deste livro do Paraná.

Percebemos que este foi construído coletivamente, através do programa de formação continuada (Projeto Folhas) de professores dessa rede de ensino, com base na realidade concreta encontrada nas suas escolas. Essa obra, elaborada para o Ensino Médio, trás como "conteúdos estruturantes": Esporte, Jogos, Ginástica, Lutas e Dança.

O livro foi construído com a participação dos professores da rede estadual de ensino na perspectiva de subsidiar educadores e educandos do ensino médio no trato com o conhecimento da cultura corporal (PARAISO, 2011, p. 190).

\footnotetext{
9 Ainda na perspectiva privada, vale destacar que algumas redes particulares de ensino, tais como, Positivo, COC, Anglo e Objetivo produziram apostilas de Educação Física (RODRIGUES, 2009; DARIDO et al., 2010).

10 Citamos os Cadernos Pedagógicos do Município do Rio de Janeiro (2014), os Caderno de Orientações Didáticas do Município de São Paulo (2006), os Guias de Orientações para a Intervenção Pedagógica do Estado do Espírito Santo (2011) e os Módulos Didáticos do Estado de Minas Gerais (2009). Todos indicados no link Cadernos Didáticos do Portal do Professor do Ministério de Educação do Brasil . Disponível em: $<$ http://portaldoprofessor.mec.gov.br/linksCursosMateriais.html? categoria=320>. Acesso em: 20 set. 2014.
} 
Essa obra estabelece uma aproximação muito forte com o livro "Metodologia do Ensino da Educação Física"(2012), adotado como uma das referências para subsidiar a sua construção. Assim, faz a opção pela cultura corporal como o seu objeto de estudo.

Em 2008 e 2009 foram publicados os livros didáticos (Cadernos do Professor e Cadernos do Aluno) respectivamente do Estado de São Paulo (SP) e do Estado do Rio Grande do Sul (RS). Esses livros destinam-se ao Ensino Fundamental e Médio, subdivididos, no caso de SP em séries/anos e volumes e no do RGS um caderno do professor e vários do aluno.

Contudo, os professores da Rede Estadual de São Paulo apresentam certa resistência ao utilizar esse material, pois alegam que, diferente do Livro Didático Público de Educação Física do Estado do Paraná, a sua construção não se deu de forma coletiva (RODRIGUES; DARIDO, 2011).

Em 2012, foi lançado o Livro Didático Público de Educação Física da Prefeitura de João Pessoa-PB ${ }^{11}$ que, por sua vez, foi construído coletivamente, por meio do programa de formação continuada dos professores de Educação Física dessa prefeitura, representando 0 primeiro livro didático público de Educação Física do Norte-Nordeste. Esse livro foi elaborado para o Ensino Fundamental e aborda, na linguagem dos estudantes, os conteúdos jogo, dança, ginástica e esporte.

Deste modo, toma como objeto de estudo a cultura corporal, com base na perspectiva Crítico-Superadora (CASTELLANI et al., 2012). As atividades expostas partem sempre de uma problematização vinculada ao cotidiano social dos alunos e retorna à ela para uma síntese do conteúdo abordado. O livro reconhece a tradição histórica que levou a Educação Física a ser considerada como uma atividade curricular destituída de teoria, mas reivindica 0 reconhecimento dialético de sua prática educativa, inclusive com a elaboração, discussão e uso do livro didático.

Enfim, com estes achados, a partir da literatura, nota-se, na área da Educação Física, um despertar para a necessidade de aproximação com o campo dos livros didáticos.

Entende-se que a publicação de estudos sobre o tema e a produção (pública ou privada) de livros didáticos na área contribui para a superação do perceptível hiato apresentado.

Em recente estudo Botelho e Neira (2014), alertam que professores não devem recorrer aos livros didáticos sem, previamente, realizar uma análise crítica de seus conteúdos e formas, sendo sensato e imprescindível usar critérios educativos para seu uso como recurso didático. E finalizam, que, em termos prospectivos, é necessário levar em consideração os dados encontrados e analisados para se elaborar e utilizar livros didáticos na área da Educação Física (BOTELHO; NEIRA, 2014).

No entanto não há consensos, nas diferentes áreas, acerca da forma e do conteúdo em sua adoção no meio educacional. E na Educação Física, diante de seu hiato histórico e seu recente despertar, há debates de sua importância ou não. Principalmente diante de uma ordenação/hierarquia/sequência de conteúdos. 


\section{CONSIDERAÇÕES FINAIS}

A relação dos livros didáticos com a Educação Física ainda é algo pouco discutido. A Educação Física ainda se apresenta, no contexto escolar, como uma disciplina que pouco estabelece proximidade com esses recursos materiais. Identificou-se que esse distanciamento deve-se à própria história da Educação Física, contemplando sua formatação legal e seu objeto de estudo, remetendo principalmente à referência de suas concepções de Educação Física que se pautavam na execução/reprodução de movimentos corporais (atividade) em detrimento da apropriação crítica do conhecimento (componente curricular).

Por outro lado, constatou-se indícios de um "despertar" para a importância e para a necessidade de se estabelecer uma relação crítica entre a Educação Física e os livros didáticos, pois percebeu-se um aumento, mesmo que pequeno, das produções (livros didáticos de Educação Física e estudos sobre o livro didático na Educação Física) a partir da publicação do primeiro livro didático público no Brasil.

Reconhecemos que Educação Física é um componente curricular obrigatório da Educação Básica, e não mais uma atividade, no sentido pejorativo, destituída de conhecimentos. Por isso devemos nos fazer presentes também no campo dos livros didáticos, sendo essa mais uma forma de reivindicar nossa isonomia perante as demais disciplinas. Porém, lembramos que a área, os docentes devem avançar frente à concepção tradicional de elaboração, discussão e uso do livro didático, empregando-o coerentemente na prática pedagógica, aproveitando-o como mais um recurso, e não o único, que pode contribuir com o processo de ensino-aprendizagem dos diversos conteúdos da Educação Física.

\section{REFERÊNCIAS}

BARDIN, Laurence. Análise de conteúdo. Lisboa: Edições 70, 2011.

BOTELHO, Rafael Guimarães; NEIRA, Marcos Garcia. Análisis de libros de texto en Brasil y en España: una introducción al tema en el área de educación física. Movimento, Porto Alegre, v. 20, n. 2, p. 659-685, abr.jun. 2014.

CARMO, Sérgio Carnevale do. 0 livro como recurso didático no ensino do futebol. 1999. 121 f. Dissertação (Mestrado em Educação Física) - Faculdade de Educação Física, Universidade Estadual de Campinas, Campinas, 1999.

CASTELLANI FILHO, Lino et al.(Org.). Metodologia do ensino da educação física. São Paulo: Cortez, 2012.

DARIDO, Suraya Cristina et al. Livro didático na educação física escolar: considerações iniciais. Motriz, Rio Claro, v. 16, n. 2, p. 450-457, abr./jun. 2010.

DINIZ, Irlla Karla dos Santos; DARIDO, Suraya Cristina. Livro didático: uma ferramenta possível de trabalho com a dança na educação física escolar. Motriz, Rio Claro, v. 18, n. 1, p. 176-185, jan./mar. 2012.

FRAIHA, Ana Lívia Gorgatto; DARIDO, Suraya Cristina; RUFINO, Luiz Gustavo Bonatto. Avaliando o processo de ensino e aprendizagem por meio de um livro didático: possibilidades 
pedagógicas do basquetebol nas aulas de educação física. Motriz, Rio Claro, v. 19, n. 3, p. S76-S381, jul./set. 2013. Supl.

GALATTI, Larissa Rafaela; PAES, Roberto Rodrigues. Livro didático e educação física: uma proposta para os jogos esportivos coletivos. Motriz, Rio Claro, v. 13, n. 2, p. S44-S343, maio/ ago. 2007. Supl. 1.

GALATTI, Larissa Rafaela; PAES, Roberto Rodrigues; DARIDO, Suraya Cristina. Pedagogia do esporte: livro didático aplicado aos jogos esportivos coletivos. Motriz, Rio Claro, v. 16, n. 3, p. 751-761, jul./set. 2010.

GOELLNER, Silvana Vilodre. Esporte moderno: memória e história. Revista Digital, Buenos Aires, v. 10, n. 77, out. 2004. Disponível em: <http://www.efdeportes.com/efd77/esporte.htm>. Acesso em: 26 jun. 2014.

GOMES-DA-SILVA, Pierre Normando. Compendio de Gymnastica Escolar: o corpo e a pedagogia no inicio do século XX. In: FERREIRA NETO, Amarílio (Org.). Pesquisa histórica na educação física. Aracruz: FACHA, 1999. v. 4, p. 27-49.

IMPOLCETTO, Fernanda Moreto; DARIDO, Suraya Cristina. Livro didático como tecnologia educacional: uma proposta de construção coletiva para a organização curricular do conteúdo voleibol. Motriz, Rio Claro, v. 19, n. 3, p. S76-S381, jul./set. 2013. Supl..

MUNAKATA, Kazumi. Investigações acerca dos livros escolares no Brasil: das ideias à materialidade. In: CONGRESO IBEROAMERICANO DE HISTÓRIA DE LA EDUCACIÓN LATINOAMERICANA. 6., 2003, San Luis Potosí. Anais. 2003. Disponível em: < http://www. academia.edu/10909984/Investiga\%C3\%A7\%C3\%B5es acerca dos livros escolares no Brasil das id\%C3\%A9ias \%C3\%A0 materialidade >. Acesso em: 26 jun. 2014.

PARAISO, Cristina Souza. O trato com o conhecimento da ginástica: um estudo sobre possibilidades de superação. Motrivivência, Florianópolis. v. 23, n. 36, p. 169-168, jun. 2011.

PAULA, Maristela Vicente de. A utilização de apoio bibliográfico como recurso metodológico para o ensino da educação física nos níveis fundamental e médio de escolarização da cidade de Catalão - GO. 2003. 161 f. Dissertação (Mestrado) - Programa de Pós-Graduação em Educação Física, Universidade de Campinas, Campinas, 2003.

RODRIGUES, Heitor de Andrade. Basquetebol na escola: construção, avaliação e aplicabilidade de um livro didático. 2009. 183 f. Dissertação (Mestrado em Ciência da Motricidade) - Universidade Estadual Paulista, Rio Claro, 2009. Disponível em: <http://www. nuteses.temp.ufu.br/tde busca/arquivo.php?codArquivo=6417\&acordo=>. Acesso em: 20 jul. 2013.

RODRIGUES, Heitor de Andrade; DARIDO, Suraya Cristina. O livro didático na Educação Física escolar: a visão dos professores. Motriz, Rio Claro, v. 17, n. 1, p. 48-62, jan./mar. 2011.

RUFINO, Luiz Gustavo Bonatto; DARIDO, Suraya Cristina. Livro didático e saúde: possibilidades para a educação física escolar. Motriz, Rio Claro, v.17, n. 1, S1-S523, jan./ mar. 2011. Supl..

SILVA, Sheila; PONTES, Gustavo; SANCHES, Luiz; PASCON, Patrícia. Livros Didáticos em Educação Física Escolar: princípios para elaboração. Motriz, v. 7, n. 1, p. 191-192, jan./jun. 2001. Supl..

SOUZA JÚNIOR, Marcílio Barbosa Mendonça de. A educação física como componente 
Dissertação (Mestrado em Educação) - Universidade Federal de Pernambuco, Recife, 1999.

SOUZA JÚNIOR, Marcílio Barbosa Mendonça de; MELO, Marcelo Soares Tavares de; SANTIAGO, Maria Eliete. A análise de conteúdo como forma de tratamento dos dados numa pesquisa qualitativa em Educação Física escolar. Movimento, Porto Alegre, v. 16, n. 3, p. 3149, jul./set. 2010.

Apoio: Programa de Fortalecimento Acadêmico da UPE (PFAUPE) e Coordenação de Aperfeiçoamento de Pessoal de Nível Superior (CAPES). 